\title{
Escherichia Coli Transfer to Food by Fruit Flies during Short Time Exposure
}

\author{
Ahmet Buyukyavuz ${ }^{1}$, Eric Benson ${ }^{2}$, Jinbo Song ${ }^{2}$, Brittany Ellis ${ }^{2}$, Inyee Han $^{1} \&$ Paul Dawson ${ }^{1}$ \\ ${ }^{1}$ Department of Food, Nutrition and Packaging Sciences, Clemson University, Clemson, SC 29634, USA \\ ${ }^{2}$ Plant and Environmental Sciences Department, Clemson University, Clemson, SC 29634, USA \\ Correspondence: Paul Dawson, Room 226B Life Science Facility, Food, Nutrition and Packaging Sciences \\ Department, Clemson University, Clemson, SC 29634-0316, USA. Tel: 864-656-1138. E-mail: \\ pdawson@clemson.edu
}

Received: May 4, $2018 \quad$ Accepted: May 18, $2018 \quad$ Online Published: May 13, 2018

doi:10.5539/jfr.v7n4p131 URL: https://doi.org/10.5539/jfr.v7n4p131

\begin{abstract}
Two separate experiments were conducted to determine the transfer of $E$. coli by fruit flies during short term exposure to apple slices and bologna. Short time exposure (1,5 and $15 \mathrm{~min})$ of flies to inoculated apple slices were tested in the first experiment to determine the transfer of $E$. coli to flies. No difference $(\mathrm{P} \leq 0.05)$ in the number of bacteria transferred to flies were found due to these exposure times. In the second experiment the transfer of $E$. coli from inoculated apple or bologna slices (5 min exposure) to un-inoculated slices $(1,5$ and 15 $\min$ exposure) were tested. More bacteria were transferred to bologna at 1 and 5 min compared to apple while the number transferred did not differ at $15 \mathrm{~min}$ exposure. The percentage of $E$. coli transferred from inoculated food to flies was low $(<0.5 \%)$ while the percentage transferred from flies to un-inoculated food was relatively high $(>50 \%)$. This study found that flies can pick up and transfer bacteria to food in short exposure times.
\end{abstract}

Keywords: fruit flies, Escherichia coli, bacterial transfer, food contamination, apple slices, bologna

\section{Introduction}

\subsection{Flies Carry Infectious Diseases}

Pathogenic viruses (Calibeo-Hayes et al., 2003; Chakrabarti et al., 2008; Otake et al., 2004; Schurrer et al., 2005; Watson et al., 2007) bacteria (Ahmad et al., 2011; Doud et al, 2014; Fleming et al., 2014; Goush et al., 2014; Soheyliniya and Barin, 2014; Wei et al., 2014) and parasites (Balla et al., 2014; Graczyk et al., 2005; Szostakowska et al., 2004) have been found on flies. Antibiotic-resistant bacteria were also isolated from flies (Ahmad et al., 2011; Wei et al., 2014). Ghosh et al. (2014) established that Enterococci persisted throughout the life cycle of house flies to colonize the gut of the adult fly while Fleming et al. (2014) found that $E$. coli survived 12 hours in the crop and rectum of house flies. Furthermore, Wei et al. (2014) reported that Proteus mirabilis lasted for 3 days in the housefly digestive tract and Gill et al. (2016) established that Campylobacter spp. survived 1, 2, 4, 8, 12 and 24 hours after inoculation.

\subsection{Flies Transmit Pathogens}

Several types of flies live in close association with humans (synanthropic); including flesh flies, house flies, fruit flies and blowflies among others (Olsen, 1998). These families of flies (Sarcophagidae, Muscidae, and Calliphoridae) have become known as filth flies that breed in animal feces, garbage and other organic matter including food (Greenberg, 1973). Synanthropic flies that land near humans have been long recognized as vectors for numerous viruses, bacteria and protozoans causing human disease and are more prevalent where poor sanitation conditions exist, particularly in urban areas (Greenberg, 1971). Bacteria that have been transmitted by flies include Salmonella spp., Shigella spp., Vibrio spp., Escherichia coli, Staphylococcus aureus, Campylobacter spp., Yersinia enterocolitica, Pseudomonas spp, Chlamydia spp. and Klebsiella spp. (Echeverria et al., 1983; Kahn and Huq, 1978; Khin et al., 1989; Fotedar et al., 1992; Bidawid et al., 1978; Fukushima et al., 1979; Fotedar, 2001; Olsen, 2001; Forster et al., 2007). Synanthropic flies also transmit common food enteropathogens Salmonella spp., Shigella spp., Campylobacter spp. or enterohemorrhagic E. coli by direct contact with humans and via contamination of food (Bidawid et al., 1978). Over 50\% of the house flies collected in a hospital were also found to be a reservoir for bacteria that were resistant to at 10 antimicrobial agents 
(Rahuma et al., 2005). Flies can also transfer pathogens to food by direct contact with body parts, vomiting and through fly feces (Olsen, 1998). Levine \& Levine (1991) reported that shigellosis could be transmitted by flies to food and eating utensils with an inoculum as low as 10-100 cells. As a result the U.S. FDA classifies flies as adulterants thus requiring that flies be prevented from establishments that handle food (De Jesus et al, 2004).

\subsection{Flies Transmit Pathogens to Food}

The capability of flies to transfer pathogens to food was determined many years ago. The relationship between the presence of flies in close proximity to food and the spread of typhoidal diarrheal disease during the Boer and Spanish-American Wars was first made in 1904 (Nash, 1904). Ortrolenk and Welch (1942) conducted a controlled laboratory study to demonstrate that flies fed on Salmonella Enteriditis-inoculated food can transfer the bacterium to other flies and food and that $S$. Enteriditis survived in the fly throughout its 4-week lifespan. Peppler (1944) found that houseflies transported Salmonella Enteriditis 3 miles from a sewage pond to a kitchen and flies carried Salmonella from processing plants to markets and homes in Mexico (Greenberg et al., 1963). Greenberg (1964) reported that when house flies were exposed to dog feces containing $10^{5} \mathrm{~S}$. Typhimurium cells/g for 2 hours, 5 out of 20 flies became infected with Salmonella containing between 43 and 635 bacteria. The infected flies were exposed to a Mexican milk drink (Atole) for 100.5 hours which were then (surprisingly) consumed by volunteers. While none of the volunteers showed signs of illness, 8 of 10 milk samples contained between 5,000 and 640,000 S. Typhimurium cells $/ \mathrm{ml}$. Other examples of flies contaminating food or food production facilities include Fukushima et al. (1979) detecting Yersinia enterocolitica from flies collected at a swine production facility and Rosef \& Kapperud (1983) isolating Campylobacter jejuni from flies at both a poultry and swine farm. Olsen and Hammack (2000) found Salmonella Enteritidis at an egg laying operation which had produced eggs implicated in $S$. Enteriditis outbreaks. Flies have been implicated as vectors in other bacterial epidemics and outbreaks including an enterohemorrhagic colitis epidemic in a Japanese nursey school had E. coli $\mathrm{O} 157: \mathrm{H} 7$ isolated from patients and flies in the area which were indistinguishable using molecular typing and the flies were traced to a nearby cattle farm (Moriya et al., 1999).

Several studies have reported that bacteria can be transferred from food to flies (Kobayashi et al., 1999; Sasaki et al., 2000; De Jesus et al., 2004). Food carrying E. coli O157:H7 that was consumed by flies proliferated and discharged the bacteria rapidly showing that flies are not simple vectors for pathogens but can increase bacterial numbers in the digestive tract (Kobayashi et al., 1999). Kobayashi et al. (1999) also reported that 6-7 logs of $E$. coli $\mathrm{O} 157: \mathrm{H7}$ in the alimentary canal immediately after feeding an inoculated sugar solution. Sasaki et al. (2000) reported that E. coli $\mathrm{O} 157: \mathrm{H} 7$ proliferated in the mouth and crop of house flies, increasing in the number of bacteria present up to 4 hours which persisted at least 4 days after feeding.

\subsection{Time Required for Transfer}

Previous studies have examined contact times with the contaminating surface of longer the 30 minutes and also how flies ingest bacteria then transfer it to food or other surfaces. For example, De Jesus et al. (2004) exposed flies to inoculated sugar/milk, potato salad and steak for $30 \mathrm{~min}$ prior to contact with clean glass jar surfaces. Greater than $1 \log$ of E. coli was detected on 43,53 , and $62 \%$ of the flies exposed to sugar/milk, steak and potato salad, respectively. De Jesus et al. (2004) further reported that contaminated flies exposed to food carrying $10^{8}$ $\mathrm{CFU} / \mathrm{g}$ transferred $10^{4} \mathrm{CFU} / \mathrm{g}$ of bacteria to clean surfaces $(0.001 \%)$. In contrast, the current study examined contact times with a contaminated surface of less than 15 minutes. Specifically, transfer of E. coli from inoculated apple to flies and from inoculated apple and bologna to un-inoculated apple and bologna during 1,5 and 15 minutes exposure times were evaluated.

\section{Methods}

\subsection{Preparation and Maintenance of Fruit Flies}

Wingless fruit flies, Drosophila melanogaster Meigen, were purchased from Carolina Biological Supply Company, Burlington, $\mathrm{NC}$ as a fruit fly culture kit. Adult fruit flies were delivered and maintained at the Clemson Urban Research Laboratory, Clemson, SC. Adult flies from the culture were placed into 28.5 X $95 \mathrm{~mm}$ polystyrene vials (VWR Fly Vials Wide PS CS500, VWR International, Radnor, PA). Vials consisted of a feeding medium, Formula 4-24® Instant Drosophila Medium (Plain), obtained from Carolina Biological Supply Company, mixed with $10 \mathrm{ml}$ of distilled water and a few granules of Fleischmann's active yeast (Associated British Foods, London, UK). Adult flies were then placed into the clean $28.5 \mathrm{X} 95 \mathrm{~mm}$ polystyrene vials (VWR Fly Vials Wide PS CS500, VWR International) to lay eggs, and a bonded dense-weave cellulose acetate vial plug (VWR International) was used to seal the vial. They were reared in a $22{ }^{\circ} \mathrm{C}$ in rearing room with the fluctuation of $20.5{ }^{\circ} \mathrm{C}-23.3{ }^{\circ} \mathrm{C}$ on 12 -h day/night light cycle. 
In order to maintain and grow fly cultures, every two weeks the same procedure was followed. Fly colonies were transferred into new polystyrene vials, which were composed of a feeding medium, $10 \mathrm{ml}$ of distilled water and a few granules of Fleischmann's active yeast. Adult flies were then placed into the clean vials to lay eggs, and sealed with the vial plug and hold in the raring room at $22{ }^{\circ} \mathrm{C}$ with the fluctuation of $20.5{ }^{\circ} \mathrm{C}-23.3{ }^{\circ} \mathrm{C}$ on $12-\mathrm{h}$ day/night light cycle. This left the remaining eggs, larvae and pupae for future adults in the now adult fly free vial. Between 2 and 7 days old fruit flies were separated from feeding vials and put in the vials (each with 20 fruit flies) at the Urban Entomology Research Laboratory in Clemson University just before use in each experiment.

\subsection{E. coli Culture Preparation}

A $2 \%$ ampicillin stock solution was prepared with distilled water and filter sterilized aseptically using a $0.45 \mu \mathrm{m}$ syringe filter (Acrodisc Sringe filters $0.45 \mu \mathrm{m}$ Supor). The stock solution was kept in the refrigerator at $4{ }^{0} \mathrm{C}$ until needed. Sixteen g Tryptic Soy Agar (TSA) added to $400 \mathrm{ml}$ distilled water in $500 \mathrm{ml}$ bottles and dissolved by stirring. The media was autoclaved at $121{ }^{\circ} \mathrm{C}$ for $15 \mathrm{~min}$ in a steam sterilizer (Steris-Amsco Lab 250, LV 250, UK). Autoclaved TSA media was cooled to $48-50{ }^{\circ} \mathrm{C}$ in a water bath Precision, Microprocessor Controlled 280 Series Water Bath). Then, $2 \mathrm{ml}$ ampicillin stock solution was mixed gently to $400 \mathrm{ml}$ media before pouring aseptically in the sterile petri dishes yielding a $0.01 \%$ ampicillin concentration in the media.

An Escherichia coli ampicillin-resistant strain with a fluorescent gene was used for the bacterial transfer and survival studies. A non-pathogenic E. coli strain JM109 was labelled with jellyfish green fluorescent protein according to the protocol as described previously (Jiang et al., 2002). The competent bacterial cells were electroporated in a Gene Pulser II (Bio-Rad, Hercules, CA) with plasmid vector pGFPuv (ClonTech, Palo Alto, CA). Transformants were selected from isolated colonies grown on Luria-Bertani agar (LB) plates containing $100 \mathrm{~g}$ ampicillin/mL. The resulting ampicillin-resistant transformants emitted bright green fluorescence under UV light. The stability of GFP label in the E. coli strain was determined by streaking on trypticase soy agar (TSA) plates containing $100 \mathrm{~g}$ ampicillin/mL for several generations. The E. coli JM 109 culture was held in a $-80^{\circ} \mathrm{C}$ freezer in vials containing tryptic soy broth (Becto ${ }^{\mathrm{TM}}$ Tryptic Soy Broth, Becton Dickinson and company Sparks, MD) supplemented with $20 \%$ (v/v) glycerol (Sigma, St. Louis, MO). The frozen vial was thawed at room temperature prior to culturing. From this thawed vial, $0.1 \mathrm{~mL}$ of culture was transferred to $10 \mathrm{~mL}$ TSB (DIFCO) containing 0.5\% ampicillin (Sigma-Aldrich, St. Louis, MO, USA) in 2 loosely screw-capped tubes and then the tubes were incubated for $16-18 \mathrm{~h}$ at $37^{\circ} \mathrm{C}$ with vigorous shaking (Thermolyne Maxi-Mix III type 65,800 , Barnstead/Thermolyne, Dubuque, IA). The second transfer was prepared from this first transfer culture by adding $0.1 \mathrm{~mL}$ from the first transfer tube to another fresh $10 \mathrm{~mL}$ TSB (DIFCO) with $0.5 \%$ ampicillin (Sigma), and again incubated for $16-18 \mathrm{~h}$ at $37^{\circ} \mathrm{C}$ with shaking.

Actively growing cultures were used for each experiment. Growth culture was centrifuged at $5000 \mathrm{rpm}$ for 15 min (Eppendorf Centrifuge $5804 \mathrm{R}, 15 \mathrm{amp}$ version, Hamburg, Germany), then the pellet re-suspended in $10 \mathrm{~mL}$ of sterile $20 \%$ sucrose solution to obtain a population of approximately $6-7 \log \mathrm{CFU} / \mathrm{mL}$. Initial cell populations were verified by enumeration of the cells following surface plating in Tryptic Soy Agar (TSA) containing $0.5 \%$ ampicillin (DIFCO ${ }^{\mathrm{TM}}$, Becton Dickinson and company Sparks, MD) and incubating at $37^{\circ} \mathrm{C}$ for $24 \mathrm{~h}$. A new inoculum was prepared on each day of the experiment.

\subsection{Experiment 1: Contact time Effects on Transfer of E. coli from Bologna and Sliced Apples to Flies}

Sliced apples were placed in the petri dishes and surface moisture of bologna and apples was patted dry with a sterile gauze. Each surface was inoculated with $0.2 \mathrm{ml}$ of a $20 \%$ sucrose solution containing approximately 6 $\operatorname{logs} / \mathrm{ml}$ of fluorescently-labelled and ampicillin resistant (to $0.5 \%$ ampicillin) $E$. coli which was then allowed to dry/attach for $5 \mathrm{~min}$ after which one vial ( 20 fruit flies) were exposed to apple slice surface for 1,5 , and 15 minutes in closed petri dishes. The flies were immediately immobilized by placement into $-30{ }^{\circ} \mathrm{C}$ for $4 \mathrm{~min}$. All of the flies were transferred into test tubes containing $5 \mathrm{ml}$ of $0.1 \%$ peptone water using sterile forceps then tubes were vortexed 3 times for 15 seconds. One hundred microliters of the solution and 10-fold serial dilutions were spread-plated on tryptic soy agar (TSA) plates supplemented with ampicillin. The apple slices and bologna on which the flies removed were placed into sterile bags including $20 \mathrm{ml} 0.1 \%$ peptone solution. After shaking for 30 second, $0.1 \mathrm{ml}$ of the solution and 10-fold serial dilutions were plated on TSA supplemented with ampicillin. All plates were incubated at $37^{\circ} \mathrm{C}$ for $24 \mathrm{~h}$ and the number of ampicillin-resistant $E$. coli was counted with a bacterial colony counter (model 3325; Leica Quebec Darkfield). Plates were examined under UV light and only fluorescent colonies were counted. Bacterial counts were converted into colony forming units per fly (cfu/fly), $\log$ cfu/fly and $\%$ transfer of cfu from apple slice to flies. The $\%$ transfer was calculated using the following formula: 


\section{E. coli recovered from flies}

$\%$ transfer $=100 \mathrm{X} \quad$ E. coli recovered from inoculated food slices $+E$. coli recovered from flies

2.4 Experiment 2: Transfer of E. coli by Fruit Flies from Contaminated Food to "clean" Food

\subsubsection{E. coli Transfer from Inoculated Apples to Clean Apples}

Gala apples were obtained from a local store and held under refrigerated conditions $\left(4{ }^{\circ} \mathrm{C}\right)$ until use within 4 hours. On the dates of each experiment, the apples were removed from refrigerator to equilibrate to $22 \pm 4^{\circ} \mathrm{C}$ approximately 1 hour, sliced with a sterile apple slicer then placed in a sterile petri dish $(60 \mathrm{~mm}$ diameter x 15 $\mathrm{mm}$ deep).

The contamination of fruit flies with E. coli was conducted in petri dishes. The sliced apples were placed in the petri dishes and surface juice of the apples slices was removed with a sterile gauze. Each apple slice was inoculated with $0.2 \mathrm{ml}$ of a $20 \%$ sucrose solution containing approximately $6 \mathrm{logs} / \mathrm{ml}$ of fluorescently-labelled and ampicillin resistant (to $0.5 \%$ ampicillin) $E$. coli after which the slice was held for $5 \mathrm{~min}$. One vial containing 20 fruit flies were exposed to the inoculated apple slices for 5 minutes in the closed petri dishes. The contaminated flies were then transferred onto clean apple slices within the petri dishes (no surface juice removed) then flies were allowed to walk on the apple surface for $5 \mathrm{~min}$. Five minutes was chosen as the contact time since this time yielded the greatest transfer for the three times tested in Experiment 1. The flies were quickly immobilized by refrigerating the petri dishes for $4 \mathrm{~min}$ and then flies were transferred into $5 \mathrm{ml} 0.1 \%$ peptone using sterile forceps. After vortexing three times for 15 second, appropriate dilutions were made and plated TSA plates supplemented with $0.5 \%$ ampicillin. The apple slices on which the flies removed were put into the sterile bags with $20 \mathrm{ml} 0.1 \%$ peptone solution. After shaking for 30 second, appropriate dilutions were made and plated TSA plates supplemented with $0.5 \%$ ampicillin. Plates were incubated at $37{ }^{\circ} \mathrm{C}$ for $24 \mathrm{~h}$ and the colonies counted. $E$. coli colonies were confirmed by examining plates under UV light.

\subsubsection{E. coli Transfer from Inoculated Bologna to Clean Bologna}

Turkey bologna meat obtained from a local market was held under refrigeration at $4{ }^{0} \mathrm{C}$ until use within 4 hours. Bologna slices were cut to the size of a petri dish bottom $(60 \mathrm{~mm}$ diameter) and placed in the petri dishes then surface juice of the bologna slices was removed with a sterile gauge. Each bologna slice was inoculated with 0.2 $\mathrm{mL}$ E. coli inoculum containing $0.1 \%$ peptone (peptone used this time instead of $20 \%$ of sugar solution) (Yee, 2003) then allowed to stand for $5 \mathrm{~min}$. Twenty fruit flies were exposed to the inoculated bologna slices for $5 \mathrm{~min}$ in the closed petri dishes. The contaminated flies were then transferred onto clean bologna slices within the petri dishes (no surface juice removed for this bologna) and allowed to walk on the bologna surface for $5 \mathrm{~min}$. The flies were quickly immobilized by refrigerating the petri dishes for 4 min and transferred into $5 \mathrm{~mL}$ of sterile $0.1 \%$ peptone. After three times vortexing for $15 \mathrm{sec}$, appropriate dilutions were made and plated onto TSA plates supplemented with $0.5 \%$ ampicillin. The bologna slices from which the flies removed were put into sterile bags with $20 \mathrm{~mL}$ of sterile $0.1 \%$ peptone solution. After shaking for $30 \mathrm{sec}$, appropriate dilutions were made and plated on TSA supplemented with $0.5 \%$ ampicillin. Plates were incubated at $37^{\circ} \mathrm{C}$ for $24 \mathrm{~h}$ and the colonies counted. E. coli colonies were confirmed by examining plates under UV light. Bacterial counts were converted into colony forming units per fly (cfu/fly), log cfu/fly and \% transfer of cfu from apple slice to flies.

The $\%$ transfer from inoculated food to flies was calculated using the following formula:

$\%$ transfer $=100 \mathrm{X} \quad$ E. coli recovered from flies

$E$. coli recovered from inoculated food slices $+E$. coli recovered from flies

The $\%$ transfer from flies to clean food slices was calculated using the following formula:

$\%$ transfer $=100 \mathrm{X} \quad \underline{\text { E. coli } \text { recovered from uninoculated food }}$

E. coli recovered from flies + E. coli recovered from uninoculated food

The $\%$ transfer from inoculated food to clean food slices was calculated using the following formula:

$\%$ transfer $=100 \mathrm{X}$

E. coli recovered from uninoculated food

E. coli recovered from inoculated food slices $+E$. coli recovered from uninoculated food 


\subsubsection{Statistical Analyses}

The experiment was replicated 3 times with 4 observations per treatment per replication. The treatment was exposure time (1,5 and $15 \mathrm{~min}$ ) and food type (apple slice and bologna). The data was analyzed to determine the effect of exposure time and food type on transfer of $E$. coli to food by flies. The main effects of exposure time and food type and their interaction were analyzed by ANOVA using the GLM procedure of SAS (2017) to determine if the main effects had a significant effect $(\mathrm{P} \leq 0.05)$ on bacterial transfer. Descriptive statistics (mean, median, standard deviation) were calculated for $\log _{10}$ cfu/slice, percent food to fly transfer, percent fly to food transfer and percent food to food transfer. Least square difference (LSD) multiple comparison procedure was also used to evaluate significant differences $(P<0.05)$ among means.

\section{Results}

\subsection{Experiment 1: Contact time Effects on Transfer of E. coli from Sliced Apples to Fruit Flies}

The contact time of flies with contaminated apple slices did not significantly affect the number of $E$. coli cells recovered from flies (Table 1). The population of bacteria recovered from inoculated apples (used in $\%$ transfer calculation) was in the $6 \mathrm{log} / \mathrm{ml}$ range which was in the same magnitude as the inoculum population used to inoculate apple slices. The $\%$ of bacteria on apples transferred to flies was below $1 \%$ which is not surprising since the surface area on flies is very small. However, there were nearly $5 \operatorname{logs}$ of $E$. coli recovered from flies after walking on inoculated apples for only $1 \mathrm{~min}$.

Table 1. Transfer of $E$. coli to flies exposed for different times from inoculated apple

\begin{tabular}{lrrrrrr}
\hline Exposure (min) & \multicolumn{3}{c}{ Log cfu } & \multicolumn{3}{c}{ \% transmission } \\
\hline & mean & \multicolumn{1}{c}{ SD $^{2}$} & max & mean & SD & max \\
\hline 1 min & 4.8 & 0.3 & 5.0 & 0.4 & 0.1 & 0.6 \\
5 min & 4.8 & 0.3 & 5.0 & 0.5 & 0.2 & 0.9 \\
15 min & 4.7 & 0.5 & 5.1 & 0.3 & 0.1 & 0.5 \\
\hline
\end{tabular}

cfu $=$ colony forming units. $n=24$

${ }^{1} \%$ transfer calculated by: $100 \mathrm{X}$

${ }^{2} \mathrm{SD}=$ standard deviation

\section{E. coli recovered from flies}

E. coli recovered from inoculated food slices $+E$. coli recovered from flies

\subsection{Experiment 2: Transfer of E. coli by Fruit Flies from Contaminated Food to "clean" Food}

Based on Experiment 1, flies were allowed to contact inoculated apple or bologna slices for 5 minutes, then they were placed in contact with "clean" apple or bologna slices for 1,5 or $15 \mathrm{~min}$. This resulted in an average of 4.5 to $5.2 \log \mathrm{cfu} / \mathrm{fly}$ of $E$. coli on flies prior to contact with un-inoculated food. The overall transfer from the inoculated food slices to the un-inoculated food slices was divided into two steps; 1-inoculated food to fly and 2 -contaminated fly to un-inoculated food. When all contact times were pooled, bologna had greater $(\mathrm{p} \leq 0.05)$ transfer of $E$. coli than apple slice (Table 2). The percent transfer from food to flies, and from food to food were greater for bologna however, when only the percent transfer from flies to food were determined, the fly to apple was greater than the fly to bologna. 
Table 2. Transfer of $E$. coli from inoculated apple or bologna slices by flies to non-inoculated slices*

\begin{tabular}{|c|c|c|c|c|c|c|c|c|c|c|c|c|}
\hline & \multicolumn{3}{|c|}{ Log cfu/slice } & \multicolumn{3}{|c|}{$\begin{array}{l}\text { Food to Fly } \\
\text { Transfer }(\%)^{1}\end{array}$} & \multicolumn{3}{|c|}{$\begin{array}{l}\text { Fly to Food } \\
\text { Transfer }(\%)^{2}\end{array}$} & \multicolumn{3}{|c|}{$\begin{array}{l}\text { Food to Food } \\
\text { Transfer }(\%)^{3}\end{array}$} \\
\hline & mean & $\mathrm{SD}^{4}$ & $\max$ & mean & SD & $\max$ & mean & $\mathrm{SD}$ & $\max$ & mean & SD & $\max$ \\
\hline apple & $4.4^{\mathrm{b}}$ & 0.06 & 5.3 & $0.14^{\mathrm{a}}$ & 0.02 & 0.50 & $56.4^{\mathrm{b}}$ & 2.6 & 95.3 & $0.11^{\mathrm{b}}$ & 0.03 & 0.87 \\
\hline bologna & $5.2^{\mathrm{a}}$ & 0.06 & 5.9 & $0.11^{\mathrm{b}}$ & 0.02 & 0.36 & $68.5^{\mathrm{a}}$ & 2.5 & 85.3 & $0.31^{\mathrm{a}}$ & 0.03 & 1.01 \\
\hline
\end{tabular}

*Flies were exposed to inoculated apple of bologna slices for 5 minutes. Values for transfer were pooled for flies contacting un-inoculated slices for 1,5 and $15 \mathrm{~min}$.

${ }^{\mathrm{a}, \mathrm{b}}$ means with different superscripts are significantly different $(\mathrm{p} \leq 0.05)$.

${ }^{1} \%$ food to fly transfer $=100 \mathrm{X}$

E. coli recovered from flies

E. coli recovered from inoculated food slices $+E$. coli recovered from flies

${ }^{2} \%$ fly to food transfer $=100 \mathrm{X}$

E. coli recovered from uninoculated food

E. coli recovered from flies $+E$. coli recovered from uninoculated food

${ }^{3} \%$ inoculated to un-inoculated food transfer $=$

$100 \mathrm{X}$

\section{E. coli recovered from uninoculated food}

E. coli recovered from inoculated food slices $+E$. coli recovered from uninoculated food

${ }^{4} \mathrm{SD}=$ standard deviation

Apples and bologna were inoculated with approximately 6 logs of E. coli cfu. The transfer of E. coli from inoculated bologna to non-inoculated bologna was greater at 1 and 5 min exposure to flies compared to the transfer from inoculated to non-inoculated apples (Figure 1). Apples had a maximum transfer of $5.3 \mathrm{log}$ cycles (93.3\% from flies to apples) of E. coli while the maximum population recovered from bologna was $5.9 \operatorname{logs}$ (85.3\% transfer) after 5 min exposure.

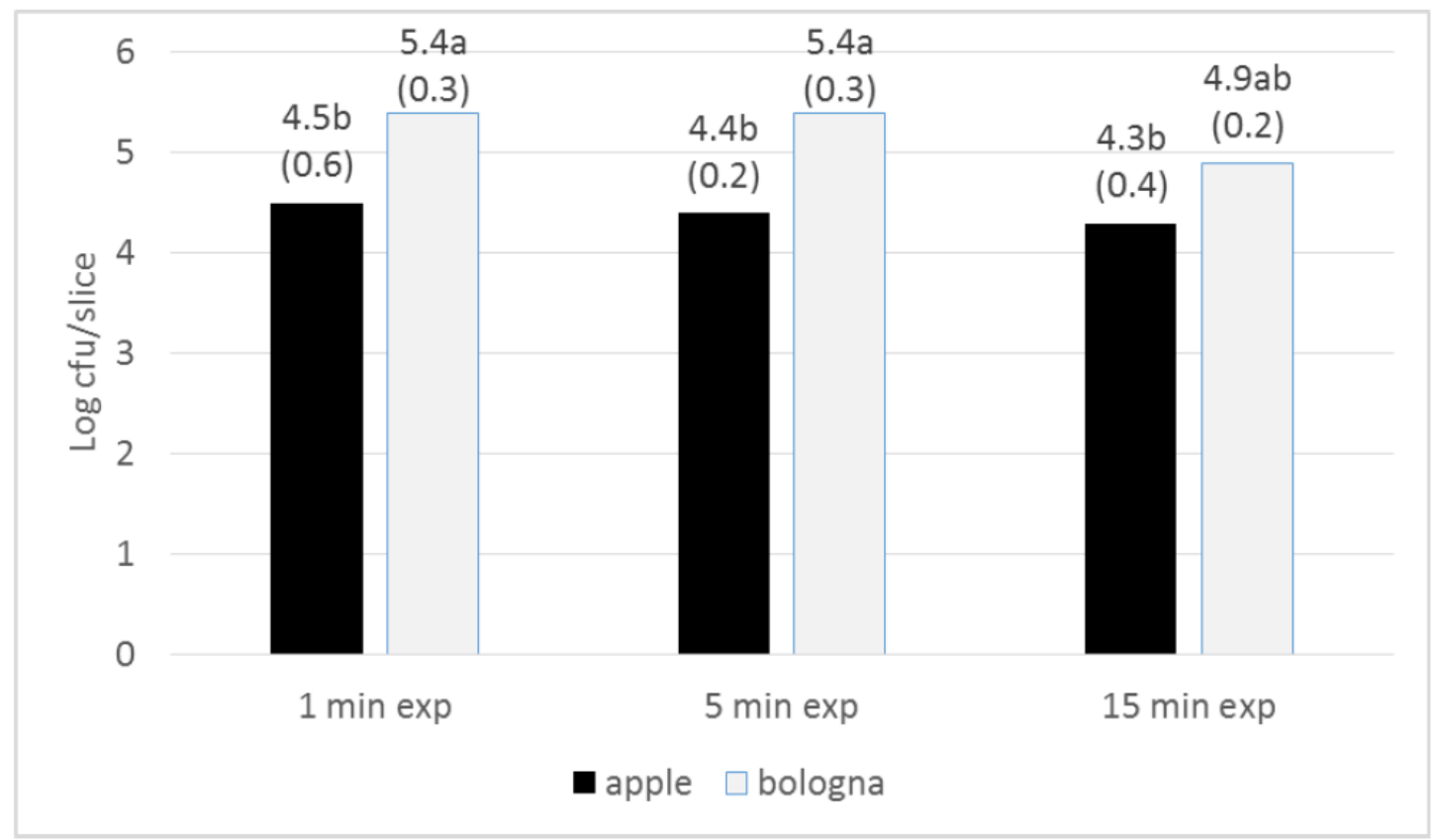

Figure 1. Log cfu/slice of E. coli recovered from apple and bologna slices after being exposed to 20 fruit flies for 1,5 or $15 \mathrm{~min}$ that had been exposed to inoculated apple or bologna for $5 \mathrm{~min}$ 
a,b means with different superscripts are significantly different $(P \geq .05) n=6$. Standard deviations are shown in parentheses below the means.

The transfer to bologna was greater primarily due to the high percentage transferred from flies to bologna (Figure 2) and not due to the transfer of $E$. coli from inoculated food to flies (Table 2). Flies in contact with the food for $1 \mathrm{~min}$ and $5 \mathrm{~min}$ had greater \% transfer from flies to food for bologna than flies in contact for $15 \mathrm{~min}$ but $\%$ transfer did not differ for apples due to exposure time (Figure 2). This indicates that flies can transfer a high percentage of bacteria from contaminated food to other foods and surfaces in a short time.

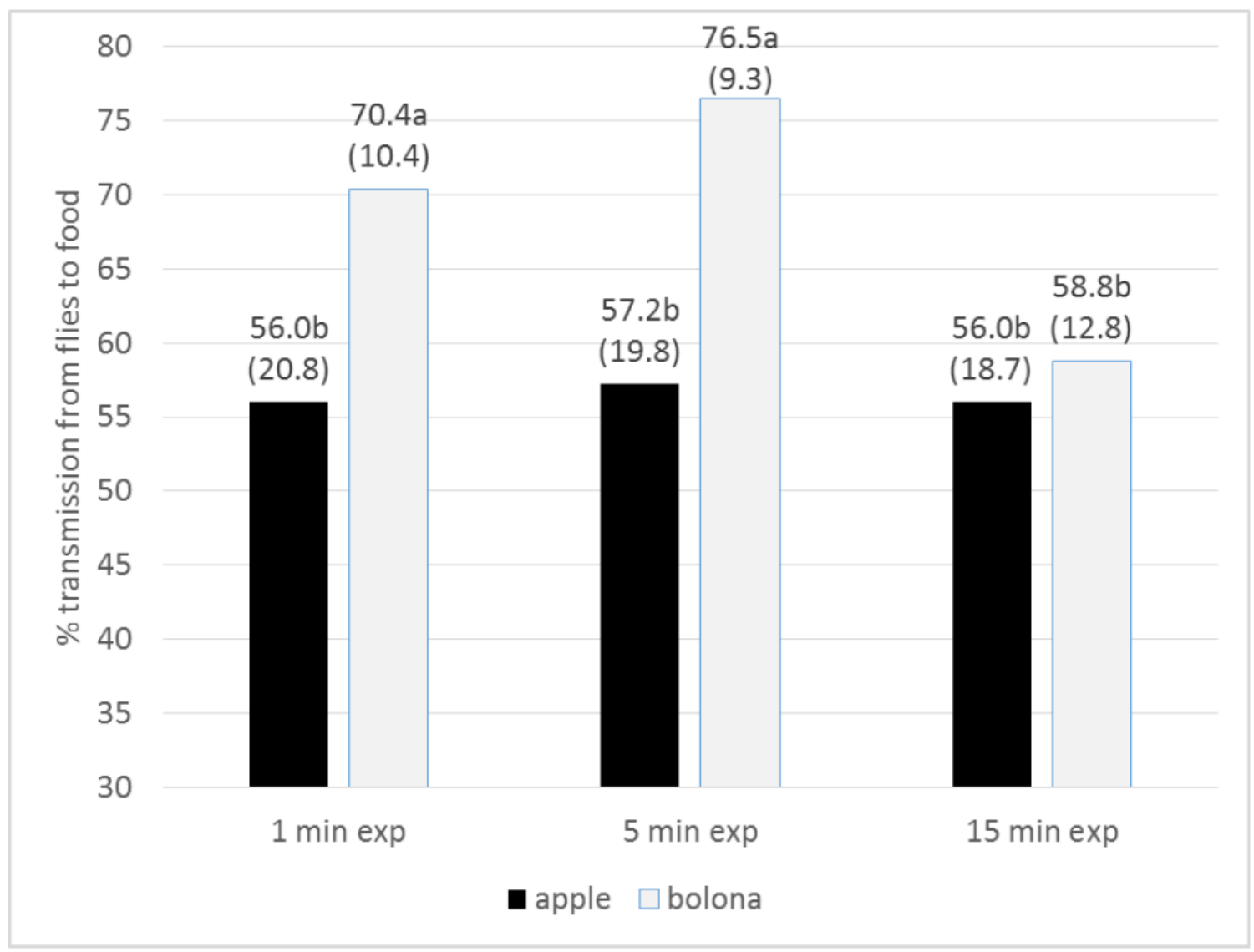

Figure 2. Percentage of $E$. coli transferred by flies to apple and bologna slices after being exposed to 20 fruit flies for 1, 5 or $15 \mathrm{~min}$ after being exposed to inoculated apple or bologna for $5 \mathrm{~min}$

${ }^{a, b}$ means with different superscripts are significantly different $(P \quad \geq \geq .05) n=6$. Standard deviations are shown in parentheses below the means.

$\%$ transfer of $E$. coli from flies to food $=100 \mathrm{X}$

\section{E. coli recovered from uninoculated food}

E. coli recovered from flies $+E$. coli recovered from uninoculated food

\section{Discussion}

Since most published research has examined the transfer of bacteria by flies during contact times of 30 min or more, the current study evaluated shorter contact times (1, 5, and $15 \mathrm{~min})$. Previous published research that evaluated short fly contact times of less than $15 \mathrm{~min}$ did not test food surfaces but focused on the mechanical action of the fly during cleaning behavior. Longer contact times allow for the fly digestive system to be more involved in transfer of bacteria. Olsen (1998) determined that, in addition to contact of body parts, flies transfer bacteria via the digestive tract through vomitus and feces. Sasaki et al. (2000) reported that excreted droplets from house flies increased from $4 \operatorname{logs} /$ droplet 1 hour after feeding to $5 \mathrm{logs} /$ droplet at 3 hours after feeding. Thus shorter contact times would be more impacted by contact of body parts on transfer bacteria from contaminated surfaces to flies and from flies to food. In one of the few short term studies done to date, Jacques et al. (2017) found the cleaning behavior of house flies and fruit flies resulted in the mechanical transmission of $E$. 
coli to sterile petri plates after 5 min exposure to inoculated plates. Gill et al. (2016) reported that house flies transmitted Campylobacter jejuni primarily by contact rather than through the digestive system even after ingestion. Contamination of food surfaces by flies requires that flies first pick up microorganisms from a contaminated surface then transfer this contamination to another food surface. To have greater control of fly contact with contaminated and un-contaminated food, wingless flies were used for the current study. Thus we first examined the effect of short term (1,5 and 15min) contact of flies with a contaminated surface and found that there was no difference in the number of bacteria picked up by flies between these contact times. The percentage of bacteria transferred to flies was very low $(\leq 0.5 \%)$ however with a highly contaminated surface as was used in this study, there were nearly $5 \log$ cycles of bacteria transferred to flies from the contaminated surface. De Jesus et al. (2004) recovered from 2.3 to $3.8 \mathrm{log}$ population of bacteria from flies after exposure to sugar-milk, potato salad or uncooked steak for $30 \mathrm{~min}$ previously inoculated with $8 \operatorname{logs}$ of E. coli O157:H7. The estimated percentage of bacteria transferred in the De Jesus et al (2004) study $(\sim 0.01 \%)$ was even lower than in the current study $(0.1$ to $0.5 \%)$ and illustrates the relatively high number of bacteria that can be transferred when the source surface is highly contaminated even with very low transfer rates. Flies typically seek highly contaminated locations where food, animal and human waste are found. This was verified by Forster et al. (2007) who found that flies collected from a dog pound, poultry house, cattle barn, horse stable and pigpen were carriers of multiple species of microorganisms, including pathogenic $E$. coli strains.

In the second experiment, the current study measured the transfer of $E$. coli from inoculated food to un-inoculated food by wingless fruit flies. The $\%$ transfer of bacteria from the inoculated food to flies was again relatively low $(<0.2 \%)$ yet comparatively, the transfer from the flies to the un-inoculated food was over 50 times higher (>50\%). Janisiewicz et al (1999) tested the transfer of $E$. coli to flies by exposing fruit flies to inoculated apple juice in filter paper for 2, 6, 24 and 48 hours and the transfer from flies to apple wounds by exposing the contaminated flies to apples for 7, 24 and 48 hours. Flies were contaminated with 8 log cfu/fly of E. coli after 2 hours and with $10 \mathrm{log}$ cfu/fly by 6 hours of contact with inoculated filter paper. The inoculated flies then transferred nearly 4 to $6 \log$ cfu/apple wound after 24 and 48 hours of exposure to food. Similar transfer of $E$. coli from contaminated apple to un-contaminated apple were found with relatively short exposure times of 1 and $5 \mathrm{~min}$ in the current study as were reported by Janiseiwicz et al. (1999).

Thus, short time exposure of flies to contaminated food and subsequent short time exposure to uncontaminated food results in transfer of relatively high numbers of bacteria.

\section{Acknowledgments}

Technical Contribution No. 6614 of the Clemson University Experiment Station.

\section{References}

Ahmad, A. Ghosh, A., Schal, C., \& Zurek, L. (2011). Insects in confined swine operations carry a large antibiotic resistant and potentially virulent enterococcal community. BMC Microbiology, 11, 23-30. https://doi.org/10.1186/1471-2180-11-23

Balla, H. J., Usman, Y., \& Muhammad, A. (2014). The role of housefly (Musca domestica) in mechanical transmission of intestinal parasites in Maiduguri Metropolis, Northeastern Nigeria. Journal of Natural Science Research, 4, 60-65.

Bidawid, S. P., Edeson, J. F. B., Ibrahim, J., \& Matossian, R. M. (1978).The role of non-biting flies in the transmission of enteric pathogens (Salmonella species and Shigella species) in Beirut, Lebanon. Annals of Tropical Medicine and Parasitology, 72, 117-121. https://doi.org/10.1080/00034983.1978.11719291

Calibeo-Hayes, D., Denning, S. S., Stringham, S. M., Guy, J. S., Smith, L. G., \& Watson, D. W. (2003). Mechanical transmission of turkey coronavirus by domestic houseflies (Musca domestica Linnaeus). Avian Disease, 47, 149-153. https://doi.org/10.1637/0005-2086(2003)047[0149:MTOTCB]2.0.CO;2

Chakrabarti, S., King, D. J., Cardona, C. J., \& Gerry, A. C. (2008). Persistence of exotic Newcastle disease virus (ENDV) in laboratory infected Musca domestica and Fannia canicularis. Avian Diseases, 52, 375-379. https://doi.org/10.1637/8173-111407-Reg

De Jesus, A. J., Olsen, A. R., Bryce, J. R., \& Whiting, R. C. (2004). Quantitative contamination and transfer of Escherichia coli from foods by houseflies, Musca domestica L. (Diptera:Muscidae). International Journal of Food Microbiology, 93, 259-262. https://doi.org/10.1016/j.ijfoodmicro.2003.12.003

Doud, C. W., Scott, H. M., \& Zurek, L. (2014). Role of house flies in the ecology of Enterococcus faecalis from wastewater treatment facilities. Microbial Ecology, 67, 380-391. https://doi.org/10.1007/s00248-013-0337-6 
Echeverria, P., Harrison, B. A., Tirapat, C., \& McFarland, A. (1983). Flies as a source of enteric pathogens in a rural village in Thailand. Applied Environmental Microbiology, 46, 32-36.

Forster, M., Klimpel, S., Mahlhorn, H., Sievert, K., Messler, S., \& Pfeffer, K. (2007). Pilot study on synanthropic flies (e.g. Musca, Sarcophaga, Calliphora, Fannia, Lucilia, Stomoxys) as vectors of pathogenic microorganisms. Parasitology Research, 101, 243-246. https://doi.org/10/1007/s00436-007-0522-y

Fotedar, R., Banerjee, U., Shriniwas, S. S., \& Verma, A. K. (1992). The house fly (Musca domestica) as a carrier of pathogenic microorganisms in a hospital environment. Journal of Hospital Infection, 20, 209-215. https://doi.org/10.1016/0195-6701(92)90089-5

Fotedar, R. (2001). Vector potential of houseflies (Musca domestica) in the transmission of Vibrio cholera in India. Acta Tropica, 78, 31-34. https://doi.org/10.1016/S0001-706X(00)00162-5

Fukushima, H., Ito, Y., Saito, K., Tsubokura, M., \& Otsuki, K. (1979). Role of the fly in the transport of Yersinia enterocolitica. Applied Environmental Microbiology, 38, 1009-1010.

Ghosh, A., Akhtar, M., Holderman, C., \& Zurek, L. (2014). Significance and survival of Enterococci during the house fly development. Journal of Medical Entomology, 5, 63-67. https://doi.org/10.1603/ME13161

Gill, C., Bahrndorff, S., \& Lowenberger, C. (2016). Campylobacter jejuni in Musca domestica: An examination of survival and transmission potential in light of the innate immune responses of the house flies. Journal of Insect Science, 24(4), 1-15. https://doi.org/10.1111/1744-7917.12353

Graczyk, T. K., Knight, R., \& Tamang, L. (2005). Mechanical transmission of human protozoan parasites by insects. Clinical Microbiology Reviews, 18, 128-132. https://doi.org/10.1128/CMR.18.1.128-132.2005

Greenberg, B., Varela, G., Bornstein, A., \& Hernandez, H. (1963). Salmonellae from flies in a Mexican slaughterhouse. American Journal of Hygiene, 77, 177-183.

Greenberg, B. (1964). Experimental transmission of Salmonella Typhimurium by houseflies to man. American Journal of Hygiene, 80(2), 149-156. https://doi.org/10.1093/oxfordjournals.aje.a120464

Greenberg B. (Ed.). (1971). Flies and Disease Vol I, Ecology, Classification, and Biotic Associations, Princeton University Press, Princeton, NJ.

Greenberg, B. (Ed.). (1973). Flies and Disease Vol II, Biology and Disease Transmission, Princeton University Press, Princeton, NJ.

Jacques, B. J., Bourret, T. J., \& Shaffer, J. J. (2017). Role of fly cleaning behavior on carriage of Escherichia coli and Pseudomonas aeruginosa. Journal of Medical Entomology, 54(6), 1712-1717. https://doi.org/10.1093/jme/tjx124

Janisewicz, W. J., Conway, W. S., Brown, M. W., Sapers, G. M., Fratamico, P., \& Buchanan, R. L. (1999). Fate of Escherichia coli $\mathrm{O} 157: \mathrm{H} 7$ on fresh-cut apple tissue and its potential for transmission by fruit flies. Applied and Environmental Microbiology, 65(1), 1-5.

Khan, A. R., \& Huq, F. (1978). Disease agents carried by flies in Dacca city. Bangladesh. Medical Research Council Bulletin, 4, 86-93.

Khin, N. O., Sebastian, A. A., \& Aye, T. (1989). Carriage of enteric bacterial pathogens by house flies in Yangor, Myanmar. Journal of Diarrhoeal Disease Research, 7(3-4), 81-84. http://www.jstor.org/stable/23498057

Kobayashi, M., Sasaki, T., Saito, N., Tamura, K., Suzuki, K., Watanabe, H., \& Agui, N., (1999). Houseflies: not simple mechanical vectors of enterohemorrhagic Escherichia coli O157:H7. American Journal of Tropical Medicine and Hygiene, 61, 625- 629. https://doi.org/10.4269/ajtmh.1999.61.625

Levine, O. S., \& Levine, M. M. (1991). Houseflies (Musca domestica) as mechanical vectors of shigellosis. Review of Infectious Diseases, 13(4), 688-698. https://doi.org/10.1093/clinids/13.4.688

Moriya, K., Fujibayashi, T., Yoshihara, T., Matsuda, A., Sumi, N., Umezaki, N., Kurahashi, H., Agui, N., Wada, A., \& Watanabe, H. (1999). Verotoxin-producing Escherichia coli O157:H7 carried by the housefly in Japan. Medical and Veterinary Entomology, 13(2), 214-216. https://doi.org/10.1046/j.1365-2915.1999.00161.x

Nash, J. T. C. (1904). Some points in the prevention of epidemic diarrhea. Lancet, 167, 892. https://doi.org/10.1016/S0140-6736(01)30147-2

Olsen, A. R. (1998). Regulatory action criteria for filth and other extraneous materials. III. Review of flies and foodborne enteric diseases. Regulatory Toxicology and Pharmacology, 28, 199-211. https://doi.org/10.1006/rtph.1998.1271 
Olsen, A. R., \& Hammack, T. (2000). Isolation of Salmonella spp. from the housefly, Musca domestica L., and the dump fly, Hydroteaea aenescens (Wiedemann) (Dipteria: Muscidae), at caged-layer houses. Journal of Food Protection, 63, 958-960. https://doi.org/10.4315/0362-028X-63.7.958

Olsen, A. R., Gecan, J. S., Ziobro, G. C., \& Bryce, J. R. (2001). Regulatory action criteria for filth and other extraneous materials: V. Strategy for evaluating hazardous and nonhazardous filth. Regulatory Toxicology and Pharmacology, 33(3), 363-392. https://doi.org/10.1006/rtph.2001.1472

Otake, S., Dee, S. A., Moon, R. D., Rossow, K. D., Trincado, C., \& Pijoan, C. (2004). Studies on the carriage and transmission of porcine reproductive and respiratory syndrome virus by individual houseflies (Musca domestica). Veterinary Record, 154, 80-85. https://doi.org/10.1136/vr.154.3.80

Peppler, H. J. (1944). Usefulness of microorganisms in studying dispersion of flies. Bulletin of the U.S. Army Medical Department, 7, 121-122.

Rahuma, N., Ghenghesh, K. S., Ben Aissa, R., \& Elamaari, A. (2005). Carriage by the housefly (Musca domestica) of multiple-antibiotic-resistant bacteria that are potentially pathogenic to humans, in hospital and other urban environments in Misurara, Libya. Annals of TropicalMedicine and Parasitology, 99(8), 795-802. https://doi.org/10.1179/136485905X65134

Rosef, O., \& Kapperud, G. (1983). Houseflies (Musca domestica) as possible vectors of Campylobacter fetus subsp. jejuni. Applied and Environmental Microbiology, 45, 381-383.

Sasaki, T., Kobayashi, M., \& Agui, N. (2000). Epidemiological potential of excretion and regurgitation by Musca domestica (Diptera: Muscidae) in the dissemination of Escherichia coli O157:H7. Journal of Medical Entomology, 37, 945-949. https://doi.org/10.1603/0022-2585-37.6.945

Schurrer, J. A., Dee, S. A., Moon, R. D., Murtaugh, M. P., Finnegan, C. P., Deen, J., Kleiboeker, S. B., \& Pijoan, C. B. J. (2005). Retention of ingested porcine reproductive and respiratory syndrome virus in houseflies. American Journal of Veterinary Research, 66, 1517-1525. https://doi.org/10.2460/ajvr.2005.66.1517

Soheyliniya, S., \& Barin, A. (2014). The role of house fly (Musca domestica) intransmission of pathogenic strains of E. coli. Journal of Veterinary Research, 69, 9-15.

Szostakowska, B., Kruminis-Lozowska, W., Racewicz, M., Knight, R., Tamamang, L., Myjak, P., \& Graczyk, T. K. (2004). Cryptosporidium parvum and Giardia lamblia recovered from feral flies. Applied Environmental Microbiology, 70, 3742-3744. https://doi.org/10.1128/AEM.70.6.3742-3744.2004

Watson, D. W., Nino, E. L., Rochon, K., Denning, S., Smith, L., \& Guy, J. S. (2007). Experimental evaluation of Msca domestica (Diptera Muscidae) as a vector for Newcastle disease. Virus Journal of Medial Entomology, 44, 666-671. https://doi.org/10.1093/jmedent/44.4.666

Wei, T., Miyanaga, K., \& Tanji, Y. (2014). Persistent of antibiotic-resitant and -sensitive Proteus mirabilis strains in the digestive tract of the housefly (Musca dimestica) and green bottle files (Calliphoridae). Applied Microbiology and Biotechnology, 98, 8357-8366. https://doi.org/10.1007/s00253-014-5846-9

Yee, W. L. (2003). Effects of sucrose concentrations and fly age on feeding responses and survival of female and male western cherry flies, Rhagoletis indifferencs. Physiological Entomology, 28, 122-131. https://doi.org/10.1046/j.1365-3032.2003.00326.x

\section{Copyrights}

Copyright for this article is retained by the author(s), with first publication rights granted to the journal.

This is an open-access article distributed under the terms and conditions of the Creative Commons Attribution license (http://creativecommons.org/licenses/by/3.0/). 